\title{
The status of diagnosis and treatment to intracranial hypotension, including $\mathrm{SIH}$
}

\author{
Jin-ping Lin ${ }^{1}$, Shu-dong Zhang ${ }^{2}$, Fei-fang $\mathrm{He}^{1 *}$, Min-jun Liu and Xiao-xu Ma ${ }^{3}$
}

\begin{abstract}
Intracranial hypotension, especially spontaneous intracranial hypotension $(\mathrm{SIH})$, is a well-recognized entity associated with cerebrospinal fluid (CSF) leaks, and has being recognized better in resent years, while still woefully inadequate. An increasing number of factors including iatrogenic factors are realized to involve in development and progression of intracranial hypotension. The diagnosis remains difficult due to the various clinical manifestations, some of which are nonspecific and easily to be neglected. Multiple imaging tests are optional in CSF leakage identification while clinicians are still confronted with difficulties when making selection resulting from superiorities and disadvantages of different imaging tests. Treatments for intracranial hypotension are multifarious but evidence is anecdotal. Values of autologous epidural blood patching (EBP), the mainstay of first-line interventional treatment currently, is getting more and more regards while there are no systematic review of its efficacy and risks. Hereby, the purpose of this review was to reveal the present strategy of intracranial hypotension diagnosis and treatment by reviewing literatures, coupled with our experience in clinical work.
\end{abstract}

Keywords: Intracranial hypotension, Imaging tests, Epidural blood patching

\section{Review}

\section{Cerebrospinal fluid physiology}

Approximately $500 \mathrm{ml}$ of cerebrospinal fluid (CSF) is produced daily, with a volume of about $150 \mathrm{ml}$ replaced three to four times everyday through the choroid plexus system for cushion the brain and spinal cord [1]. As measured using manometry in lateral position via lumbar puncture, CSF opening pressure in adults is 70$200 \mathrm{~mm} \mathrm{H}_{2} \mathrm{O}$ related with body mass index (BMI), the larger BMI is, the higher CSF pressure is [2-4]. In children, larger pressure variance and higher opening pressure ranges were demonstrated [5] while no normative data on the elder's CSF pressure was found.

\section{Epidemiology}

Intracranial hypotension, including spontaneous intracranial hypotension $(\mathrm{SIH})$ which was firstly described by Schaltenbrand in 1938, arises and clinical symptoms appear when the CSF pressure beyond the auto-regulation.

\footnotetext{
*Correspondence: zjdxsrr@163.com

'Department of Anesthesiology \& Pain Management, Center for Intracranial Hypotension Management, Sir Run Run Shaw Hospital, School of Medicine, Zhejiang University, \#3 East Qingchun Road, Hangzhou 310016, Zhejiang Province, People's Republic of China

Full list of author information is available at the end of the article
}

The associated prevalence and incidence has been estimated at 2-5:100,000, [6-10], with the higher in large scale comprehensive hospital and the lower in local health-center. Female are affected twice to fifth as often as males $[8,11]$. The peak incidence is in $30-50$ year-old although it also occurs in children and the aged $[8,11-16]$.

\section{Etiology}

It is generally known that CSF leakage is the most common feature of intracranial hypotension, and substantial majority of cases had cervical or thoracic localization of CSF leakage $[11,13]$ while the specific etiology of underlying spontaneous CSF leaks remains largely undetermined. For sure, various dural weakness, either congenital or contrived, ranging from simple dural tears to multi-level complex meningeal diverticula, allows CSF to leak into the epidural $[17,18]$. Above all, patients with symptomatic intracranial hypotension with a history of dural puncture should be first consideration [19]. Minor trauma, mainly refer to tumble, is reported in $80 \%$ patients [20]. Connective tissue disorders such as Marfan syndrome, polycystic kidney disease, Ehlers-Danlos syndrome Type II, neurofibromatosis and Lehman syndrome are also involved in spinal CSF leakages which all 
associated with genetic heterogeneity [11, 21-24]. As we mentioned above, female are affected twice to fifth as often as males, and this suggests female hormone mediated effects on dural integrity $[8,11]$. Attention should be paid on vertebral osteophytic spur which can result in dural puncture reported by Williams [25]. Additionally, other relevant factors include malnutrition [26], short stature [27] and etc. Some specialists demonstrated that CSF leakage at the skull base may not associated with orthostatic headaches [13, 28], and this hypothesis was approved clearly by Schievink in 2012 [13]. Until now, no significant data suggested that SIH is caused by decreased CSF secretion or generalized CSF hyperabsorption [28].

\section{Clinic features}

Intracranial hypotension is characterized by diffuse pachymeningeal enhancement on cranial MRI features, low CSF pressure and orthostatic headaches mostly caused by the dural puncture entitled postdural puncture headache $(\mathrm{PDPH})[1,29,30]$ with a 4 to $50 \%$ incidence calculated by researchers [31-33]. Orthostatic headache is defined as development or aggravation of headache when patients move from a supine to an upright position for seconds or minutes and headache disappears or typically relieves after lay down for a while [1, 34-36]. According to Monro-Kellie hypothesis, the CSF leakage reduces the CSF pressure and may give rises to a venous dilatation which is considered to cause headache via meningeal traction and subdural effusions, hematomas via the rupture of bridging veins [37, 38]. Dramatically, the orthostatic headache is not diagnostic and features of it sometimes are variable. It might be gradual or thunderclap in onset $[8,39]$, less or more positional over time, even intermittent [40], no relationship with position [41] or become worse when lying down [42], and the intensity of headache was variable [12] or absence of headache [12, 43]. Lagrand [44] reported a severe SIH case of orthostatic unconsciousness might caused by diencephalic herniation [45, 46]. Other cardinal symptoms reported are nausea and vomiting occurred in about half of patients [8, 47], always accompanied by neck pain stiffness [26], blurred vision [12], "visual" filed defects and diplopia [48], cough headache [30], facial pain or numbness [49], tinnitus [41], taste alternations $[8,47]$ and limb paresthesias [50] and transient third cranial nerve palsy [51]. Neurocognitive decline such as dementia $[52,53]$, behavioral changes [54-56] and parkinsonism [57] also can be presented which is rarer but has also been report.

\section{Diagnose and image features}

The diagnosis of intracranial hypotension is based on the combination of medical history, clinical features and imaging findings [58]. However, due to the woefully inadequate awareness of it, the ratio of initial misdiagnosis and missed diagnosis is pretty high, and it also make contribute to the long mean time (13 months) from symptom onset to diagnosis [47], eventually the headache disorder can evolve into a chronic daily headache pattern [59]. In order to improve the terrible situation of diagnosis and treatment and perfect guide significance, The International Headache Society developed the $3^{\text {rd }}$ diagnostic criteria (Table 1) [60] for SIH in 2013 on the basis of the criteria developed previously [61] which was too restrictive for clinic works [34, 62]. Compared with the $2^{\text {nd }}$ criteria allowing the diagnosis to be made with the absence of abnormal imaging results [34] and the one proposed by Mea [62] et al., the $3^{\text {rd }}$ criteria requires documentation of low CSF pressure and an association of the low pressure with the headache, and there should be a CSF pressure of $<60 \mathrm{~mm} \mathrm{H}_{2} \mathrm{O}$ or evidence of CSF leakage on imaging. Exclusion of other disorders is necessary such as postpartum, venous sinus thrombosis and subdural hematoma which are well known to cause positional headache [63].

Intracranial hypotension is a well-recognized entity associated with CSF leakage [54]. Multiple imaging methods are highly applicative and valuable for suspicious CSF leakage diagnosis [34], while some matters are needed.

\section{Cranial CT}

Bilateral subdural hematomas, effacement of the subarachnoid cisterns and ventricular collapse are shown as CSF leakage features by brain CT. However, despite brain $\mathrm{CT}$ does not provide as many cardinal features as MRI, it is prior to more definitive imaging in the outpatients or emergency department setting and it is a helpful initial diagnostic tool for its non-invasive.

\section{Cranial MRI}

Generally, there are some nonspecific characteristic imaging features most often associated with SIH. Subdural fluid collection which is the most common feature $[8,26,64]$, pachymemningeal enhancement, engorgement of venous structures, pituitary hyperemia and sagging of the brain relevant with effacement of perichiasmatic cisterns, bowing of the optic chiasm, flattening of

Table 1 International Classification of Headache Disorders (ICHD) diagnostic criteria for $\mathrm{SIH}$ [60]

A. Any headache fulfilling Criterion B

B. Headache has developed in temporal relation to low CSF pressure or CSF leakage, or has led to its discovery

C. Low CSF pressure $\left(<6 \mathrm{~cm} \mathrm{H} \mathrm{H}_{2} \mathrm{O}\right)$ and/OR evidence of CSF leakage on imaging

D. Not better accounted for by another ICHD-3 Diagnosis 
the pituitary stalk and pons, effacement of the prepontine cisterns, descent of the cerebellar tonsils within the posterior fossa and so on. And yet, $20-30 \%$ of patients with SIH may have a normal brain MRI $[12,34,58,65]$.

\section{Spinal MRI}

Efficiency of spinal MRI in localizing CSF leaks is lower than CT myelography (CTM), while some specific spinal manifestations of CSF leaks can be demonstrated in it such as dilated epidural and intradural veins, dural enhancement and meningeal diverticulae [66, 67]. Although plain spinal MRI may yield false-negative results because a collapse of the dural sac and epidural CSF accumulations are easily missed, it is still an excellent method of demonstrating the extent of ventral spinal CSF leaks.

\section{Myelography}

CTM and intrathecal gadolinium magnetic resonance myelography (Gd-MRM) both have higher sensitivity and better spatial resolution to localize spinal CSF leaks when compared with radionuclide cisternography. Standard CTM is best to localize suspected slow leaks and dynamic CTM is best to localize suspected fast leaks, which would otherwise spread over many levels, obscuring the actual leakage site [25, 68]. Generally, GdMRM has higher sensitivity than CTM for small, slow leaks, and is the optimum selection for spinal meningeal diverticula and dural ectasia in patients no leak was identified on a prior CTM, but it is more complex to perform [69]. Despite increased sensitivity, CTM and Gd-MRM fail to identify a CSF leak in close to $30 \%$ of subjects with suspicious SIH $[68,69]$. So for contrastenhanced Gd-MRM, the intrathecal injection of contrast medium is straightforward and safe which can be performed in the case of suspicious findings on unenhanced images [70-72].

\section{Radionuclide Cisternography}

When intracranial hypotension is suspicious, the use of radionuclide cisternography does have some value. The main features of it are slow ascentalong the spinal axis and a relative lack of activity over the convexities. Radionuclide Cisternography has been largely superseded by CTM and is increasingly considered obsolete due to its poor resolution and non-invasive quality of CTM [8, 70, 72, 73]. Its limited usefulness as the site of CSF leak remains unknown in up to one third of patients [74].

Spinal CSF leakage can be identified in most, but not all, intracranial hypotension cases. In those without a demonstrable leakage by imaging tests, it has been postulated that the spinal CSF leak is intermittent or below the level of detection of current imaging techniques [13], so the time when to take imaging tests is in significance.

\section{Treatment}

Intracranial hypotension often recovered spontaneously and no further treatments are needed [75, 76]. Although evidence is anecdotal [32, 77, 78], conservative medical management should be processed when SIH is highly suspected while necessary auxiliary examinations proceeding and many patients respond to it alone $[8,12]$. For mild intracranial hypotension patients, conservative approaches include strict bed rest, appropriate liquid, caffeine and theophylline, analgesic, non-steroidal drugs and abdominal binders [25, 59, 77-79]. Using steroids remains controversial, which might be beneficial for regulating negative feedback of nervous and immune system. For $\mathrm{PDPH}$, vasodilator agent therapy (mixture of $5 \% \mathrm{CO}_{2}$ and $95 \% \mathrm{O}_{2}$ with flow $5-10 \mathrm{ml} / \mathrm{h}$ ) is optional and very effective by dilating vessel, lower vascular obstruction and increase CSF secretion while other conservative measures are less efficient for it [80].

When initial conservative approaches fail to bring relief of clinical symptoms and for moderate and severe patients, antilogous epidural blood patching (EBP) should be considered, it is current the mainstay of firstline interventional treatment and universally effective, especially there are explicit leakage [12, 34, 79, 81-84]. EBP is the optimum method for PDPH and also can be applied reasonably in SIH [25, 85]. Repeated EBPs should be offered according to at least one-fourth of patients are not cured by one blood patch and about $50 \%$ cases require more than one blood patch $[81,82]$. Repeated EBPs are efficacious in many refractory SIH [86]. Obviously, the management of patients whose symptoms persist despite two or more EBPs performed becomes increasingly difficult and complex [35, 54, 84].

Surgery should be considered for patients whose leak sites are clearly identified and no adequate response to all non-surgical measures has been observed and two or more EBPs had been performed [6, 15, 34, 87]. Surgeries include ligation of leaking meningeal diverticula, direct repair of dural tears, packing of the epidural space with fibrin glue or strengthening the dura with a duroplasty [88]. Seriously, these surgical methods are insufficient of evidence and should be carried out by specialists with empiric in managing refractory $\mathrm{SIH}$.

There is approximate $0.5-1 \%$ of all headache presentations to Emergency Department [10]. In keeping with the case Lagrand [44] reported, very few patients characterized by alterations in conscious levels leading to coma or even death, which caused by severe sagging brain, subdural hematoma or venous sinus thrombosis. In emergency, adequate amount of intrathecal saline infusion can be a useful temporizing measure to normalize 
the intracranial pressure and so gain time to investigate and correct the CSF leak [89], as Stephen described in an instructive case report [90]. In addition, same with other surgical measures, the surgical evacuation of subdural hematomas is still in dispute, and only can be provided after the leakage of cerebrospinal fluid was handled.

\section{Information of EBP}

SIH was firstly described by Schaltenbrand in 1938 and EBP was firstly introduced for treatment of PDPH in 1960 by Gormley. EBP means injecting antilogous venous blood into epidural space within minutes in prone position under aseptic conditions. EBP acts as a mass lesion compressing the dura and raising intracranial pressure by increasing CSF volume [35, 91-93], the blood clot which formed to seals off the dural hole [94-96] and finally the CSF leak stops. Hereby, this might be the reason saline used in epidural injection is no longer currently because it fails to close the hole in the dura causing persistent CSF volume loss [84, 97]. In clinic, when the location of CSF leakage is unclear, blind EBP is recommended from lumbar avoiding performing it through an in situ epidural catheter as lumbar puncture [35]. Controversially, in Szeinfeld's opinion, a same injection site of EBP with the lumbar puncture site is advisable [98]. Alternatively, if the CSF leakage identified, target $E B P$ should be provided under $\mathrm{CT}$ or fluoroscopic guidance with a 50 to $100 \%$ symptomatic improvement rate $[64,82,99-102]$. The success rate is best in these receiving a target blood patch at the symptom onset, but this need to be balanced against the higher potential of complications [59]. For instance, due to the anatomy, the epidural space becoming smaller from the lumbar ascend to the cervical region, it is technically more challenging for clinician to perform epidural punctures in the upper thoracic and cervical spine [54].

Still, the volume of blood optimizes the efficacy of an EBP remains uncertain [76]. Inconsistently, the recommended volumes for EBP which has no business with the height of the patients [31] range from $10 \mathrm{ml}$ up to $20 \mathrm{ml}$ after clinicians attempted various volume of blood ranged over 2 to $50 \mathrm{ml}[9,54,98,103-106]$, and the largest volume was $130 \mathrm{ml}$ performed by Graff [26]. A higher success rate was reported using nearly $20 \mathrm{ml}$ [106, 107]. Griauzde [54] and Ohtonari [108] recommends using a large-volume blood patch in multiple CSF leak sites and refractory cases through a singlecatheter access site for the treatment of $\mathrm{SIH}$, and this is partially contrary with Taivain's opinion that a larger volume EBP in adults does not produce a better effect on PDPH with a standard $10 \mathrm{ml}$ volume [31]. Based on the above comprehensive situation, it is particularly necessary to point out that the EBP procedure should be discontinued when the patient complain pain in the back or legs [98] regardless of the volume of injected blood.

However, there are no controlled studies about of antilogous EBP in CSF leaks yet [21], utilization of it has just been based on the clinical observation of its effectiveness [34]. It is considered initially successful when headache disappeared completely instantaneous, always during the $2 \mathrm{~h}$ recovery room follow-up, and the success rate was about $84.5-97.5 \%$, while the overall success rate with a permanent cure was only $61 \%$ which might resulted from psychological factors $[9,31,104]$. In our institute, significant clinical improvement was obtained in $183 \mathrm{SIH}$ patients after targeted EBP was performed once $(88 \%)$, twice $(7 \%)$ or thrice $(5 \%)$ on the first admission, without the long-term follow-up achieved.

Some factors are involved in the success rate of EBP. For instances, using the Trendelenburg position before, during and after the EBP procedure has been reported to improve the success rate in over half of cases $[12,65]$ because this position might reduce the flow of spinal CSF fistula [12] and anti-Trendelenburg position increased the flow of CSF leaks [109]. Inadequate blood volumes, early patching, steroids in the epidural space and dural punctures performed with large bore needles were postulated to be possible causes of EBP failure [27, 110]. Another contested issue is utility of target EBP. Ferrante [12] claimed that providing EBP from lumbar as effective as CTdirected EBP even the leaks are identified, this opinion is in conflict with majority clinicians' proposition $[31,35]$. It is well acknowledged that acetazolamide might avoid the rebound intracranial hypertension sometimes reported after the EBP [111], in Ferrante's research whether the use of acetazolamide improved the success rate is unknown, further investigation are needed.

Agree with other authors' advise [12, 82], we also recommend days of conservative treatments before using EBP, perform EBP precociously few days after the beginning of symptoms [59]. Avoiding lumbar puncture in typical cases because such a procedure aggravates CSF seep and normal CSF pressure does not exclude the diagnosis of intracranial hypotension. In severe case, even with complications as coma and second lumbar EBP failed, invasive test should be rejected as much as possible and a target EBP is more effective than the lumbar one $[12,112]$.

It would be specially mentioned that some complications of EBP exit though they are rare and usually not long-lasting. They are inclusive of cranial nerve palsies, intracranial hypertension, paraparesis, cauda equina syndrome, aseptic arachnoiditis, chemical or infectious meningitis, subdural and subarachnoid hematoma, 
pneumocephalus, and so on [31, 96, 113-115]. Repeated injections of blood into the epidural space may potentially lead to fibrosis and obliteration of the epidural space $[35,104,105]$, so it is vitally important for clinicians to balance the advantages and drawbacks of repeat EBPs.

\section{Prevention of iatrogenic risk factors}

Risk factors for intracranial hypotension are variable and some are avoidable. Despite the nonmodifiable risk factors such as age, female gender, lower BMI, history of prior PDPH and chronic headache, modifiable risk factors play crucial roles in the occurrence and prognosis of orthostatic headache, hence, imperative concern should be paid on it such as shape, size of spinal needle, bevel orientation and angle of insertion, and even the operator experience.

Adequate needle shape like Atraumatic needle including Sprotte and Whitacre reduces the incidence of PDPH because dural holes created by it are more likely to close and return to their original position after the needle withdrawn and minimizing the damage to the dura [116-121]. In order to overcome the disadvantage of Atraumatic needles such as deeper insertion, dull tip makes it more difficult to penetrate the skin [19], the use of an 18-gauge introducer together with the spinal needle can help circumvent the difficulty with skin penetration [94].

Gilland [2] demonstrated that statistically significant were observed in CSF pressure using 22-gauge needle and 26-gauge needle, the smaller gauge the needle is, the lower CSF pressure is. The best estimate of the true CSF pressure should be the one obtained with a 26-gauge needle, which is an often overlooked principle in clinic practice. However, in young cases, a high incidence of PDPH has been reported even use 26-gauge needle dew to the dural hole exists created by it and the pressure gradient [122-124]. Geurts [91] and Tourtellott [124] revealed that the incidence of PDPH and backache were much higher using 22-gauge and 25-gauge needles than 29-gauge ones, and there were no PDPH had been observed when using the latter, and sizes of needles are non of business with respect to obtaining adequate spinal anaesthesia and spread of blockade. However, the smaller needle is, much more difficult the procedure is. Moreover, PDPH is less common if the bevel of a traumatic needle of any design is oriented and removed parallel to the long axis of the spine rather than perpendicular to it to reduced injury for branching elastic fibers resulting in a smaller dural opening [33, 125-127]. All above information on needles are instructive for clinic work according to different purposes.

Although bed rest, hydration, the volume of CSF removed during dural puncture, times of attempts and pretreatment with oral and intramuscular caffeine have not been shown to be associated with reduced PDPH incidence [32, 77, 128, 129], prophylaxis with intravenous caffeine resulted in significantly lower pain scores, less severe headaches, and decreased analgesic use compared to placebo [130]. Using frovatriptan and acetazolamide pretreatment might be protective [12, 131]. It is equally important that lower incidence of inadvertent dural puncture during epidural anesthesia was observed among experienced clinicians [96, 132]. In short, the skills of clinicians are vital in intracranial hypotension diagnosis and treatment, especially in invasive measures.

\section{Conclusions}

Intracranial hypotension, especially $\mathrm{SIH}$, is much more common than generally realized and poses considerable diagnostic and treatment challenges. There are still so many controversies on its treatment, so innovative therapies should be investigated because some patients are refractory to any treatment. The most urgent thing is that our clinicians should improve the awareness and skills in intracranial hypotension diagnosis and treatment.

\section{Acknowledgements \\ The authors would like to express their appreciations to Schievink, Mokri and other specialists for their endeavors in intracranial hypotension diagnosis and treatment. Gratitude also been expressed to Jian-min Si, Da-chun Zhou, Shu-ming Tian, Hong-wei Wang for their suggestions and guidance during investigation and critical review of this manuscript.}

\section{Funding}

This work was supported by the Health and Family Planning Commission of Zhejiang Province (20162YB159) and the National Natural Science

Foundation of China (81302070, 81372623).

\section{Authors' contributions}

JPL wrote the manuscript. JPL and SDZ collected literatures and data. JPL, SDZ and MJL conducted the analysis of pooled data. FFH and XXM proofread and revised the manuscript. All authors read and approved the final manuscript.

Competing interests

All the authors declare no competing interests in this review.

\section{Author details}

${ }^{1}$ Department of Anesthesiology \& Pain Management, Center for Intracranial Hypotension Management, Sir Run Run Shaw Hospital, School of Medicine, Zhejiang University, \#3 East Qingchun Road, Hangzhou 310016, Zhejiang Province, People's Republic of China. ²Department of Gastroenterology, Sir Run Run Shaw Hospital, School of Medicine, Zhejiang University, \#3 East Qingchun Road, Hangzhou 310016, Zhejiang Province, People's Republic of China. ${ }^{3}$ Department of Anesthesiology, Sir Run Run Shaw Hospital, School of Medicine, Zhejiang University, \#3 East Qingchun Road, Hangzhou 310016, Zhejiang Province, People's Republic of China.

Received: 19 October 2016 Accepted: 7 December 2016

Published online: 13 January 2017

\section{References}

1. Bezov D, Lipton RB, Ashina S (2010) Post-dural puncture headache: part I diagnosis, epidemiology, etiology, and pathophysiology. Headache 50: $1144-52$ 
2. Gilland O, Tourtellotte WW, O'Tauma L, Henderson WG (1974) Normal cerebrospinal fluid pressure. J Neurosurg 40:587-93

3. Corbett JJ, Mehta MP (1983) Cerebrospinal fluid pressure in normal obese subjects and patients with pseudotumor cerebri. Neurology 33:1386-8

4. Whiteley W, Al-Shahi R, Warlow CP, Zeidler M, Lueck CJ (2006) CSF opening pressure: reference interval and the effect of body mass index. Neurology 67:1690-1

5. Avery RA, Shah SS, Licht DJ, Seiden JA, Huh JW, Boswinkel J, Ruppe MD, Chew A, Mistry RD, Liu GT (2010) Reference range for cerebrospinal fluid opening pressure in children. N Engl J Med 363:891-3

6. Schievink WI, Morreale VM, Atkinson JL, Meyer FB, Piepgras DG, Ebersold MJ (1998) Surgical treatment of spontaneous spinal cerebrospinal fluid leaks. J Neurosurg 88:243-6

7. Schievink WI, Roiter V (2005) Epidemiology of cervical artery dissection. Front Neurol Neurosci 20:12-5

8. Schievink WI (2006) Spontaneous spinal cerebrospinal fluid leaks and intracranial hypotension. JAMA 295:2286-96

9. Tarkkila PJ, Miralles JA, Palomaki EA (1989) The subjective complications and efficiency of the epidural blood patch in the treatment of postdural puncture headache. Reg Anesth 14:247-50

10. Schievink WI, Maya MM, Moser F, Tourje J, Torbati S (2007) Frequency of spontaneous intracranial hypotension in the emergency department. J Headache Pain 8:325-8

11. Schievink WI, Gordon OK, Tourje J (2004) Connective tissue disorders with spontaneous spinal cerebrospinal fluid leaks and intracranial hypotension: a prospective study. Neurosurgery 54:65-70

12. Ferrante E, Arpino I, Citterio A, Wetzl R, Savino A (2010) Epidural blood patch in trendelenburg position pre-medicated with Acetazolamide to treat spontaneous intracranial hypotension. Eur J Neurol 17:715-9

13. Schievink WI, Schwartz MS, Maya MM, Moser FG, Rozen TD (2012) Lack of causal association between spontaneous intracranial hypotension and cranial cerebrospinal fluid leaks. J Neurosurg 116:749-54

14. Mokri B (2004) Low cerebrospinal fluid pressure syndromes. Neurol Clin 22 55-74, vi

15. Cohen-Gadol AA, Mokri B, Piepgras DG, Meyer FB, Atkinson JL (2006) Surgical anatomy of dural defects in spontaneous spinal cerebrospinal fluid leaks. Neurosurgery 58:238-245

16. Schievink WI, Maya MM, Louy C, Moser FG, Sloninsky L (2013) Spontaneous intracranial hypotension in childhood and adolescence. J Pediatr 163:504-10

17. Schievink WI, Reimer R, Folger WN (1994) Surgical treatment of spontaneous intracranial hypotension associated with a spinal arachnoid diverticulum. Case report. J Neurosurg 80:736-9

18. Schievink WI, Jacques $L$ (2003) Recurrent spontaneous spinal cerebrospinal fluid leak associated with "nude nerve root" syndrome: case report. Neurosurgery 53:1216-8

19. Ahmed SV, Jayawarna C, Jude E (2006) Post lumbar puncture headache: diagnosis and management. Postgrad Med J 82:713-6

20. Beckhardt RN, Setzen M, Carras R (1991) Primary spontaneous cerebrospinal fluid rhinorrhea. Otolaryngol Head Neck Surg 104:425-32

21. Schievink WI, Torres VE (1997) Spinal meningeal diverticula in autosomal dominant polycystic kidney disease. Lancet 349:1223-4

22. Ferrante E, Citterio A, Savino A, Santalucia P (2003) Postural headache in a patient with Marfan's syndrome. Cephalalgia 23:552-5

23. Davenport RJ, Chataway SJ, Warlow CP (1995) Spontaneous intracranial hypotension from a CSF leak in a patient with Marfan's syndrome. J Neurol Neurosurg Psychiatry 59:516-9

24. Erkulvrawatr S, El GT, Hawkins J, Green JB, Srinivasan G (1979) Intrathoracic meningoceles and neurofibromatosis. Arch Neurol 36:557-9

25. Williams EC, Buchbinder BR, Ahmed S, Alston TA, Rathmell JP, Wang J (2014) Spontaneous intracranial hypotension: presentation, diagnosis, and treatment. Anesthesiology 121:1327-33

26. Graff-Radford SB, Schievink WI (2014) High-pressure headaches, lowpressure syndromes, and CSF leaks: diagnosis and management. Headache 54:394-401

27. Fry RA, Perera A (1989) Failure of repeated blood patch in the treatment of spinal headache. Anaesthesia 44:492-3

28. Levine DN, Rapalino O (2001) The pathophysiology of lumbar puncture headache. J Neurol Sci 192:1-8

29. Takeuchi S, Nagatani K, Otani N, Nawashiro H (2011) PRES after spinal anesthesia. J Headache Pain 12:389, author reply 391
30. Ferrante $E$ (2013) Modified valsalva test differentiates primary from secondary cough headache. J Headache Pain 14:91

31. Taivainen T, Pitkanen M, Tuominen M, Rosenberg PH (1993) Efficacy of epidural blood patch for postdural puncture headache. Acta Anaesthesiol Scand 37:702-5

32. Lin W, Geiderman J (2002) Myth: fluids, bed rest, and caffeine are effective in preventing and treating patients with post-lumbar puncture headache. West J Med 176:69-70

33. Evans RW, Armon C, Frohman EM, Goodin DS (2000) Assessment: prevention of post-lumbar puncture headaches: report of the therapeutics and technology assessment subcommittee of the american academy of neurology. Neurology 55:909-14

34. Schievink WI, Dodick DW, Mokri B, Silberstein S, Bousser MG, Goadsby PJ (2011) Diagnostic criteria for headache due to spontaneous intracranial hypotension: a perspective. Headache 51:1442-4

35. Ho KY, Gan TJ (2007) Management of persistent post-dural puncture headache after repeated epidural blood patch. Acta Anaesthesiol Scand 51: 633-6

36. Vilming ST, Kloster R (1997) Post-lumbar puncture headache: clinical features and suggestions for diagnostic criteria. Cephalalgia 17:778-84

37. Mokri B (1999) Spontaneous cerebrospinal fluid leaks: from intracranial hypotension to cerebrospinal fluid hypovolemia-evolution of a concept. Mayo Clin Proc 74:1113-23

38. Garcia-Morales I, Porta-Etessam J, Galan L, Lagares A, Molina JA (2001) Recurrent subdural haematomas in a patient with spontaneous intracranial hypotension. Cephalalgia 21:703-5

39. Schievink WI, Wijdicks EF, Meyer FB, Sonntag VK (2001) Spontaneous intracranial hypotension mimicking aneurysmal subarachnoid hemorrhage. Neurosurgery 48:513-6, discussion 516-7

40. Mokri B (2001) Spontaneous intracranial hypotension. Curr Neurol Neurosci Rep 1:109-17

41. Schievink WI, Smith KA (1998) Nonpositional headache caused by spontaneous intracranial hypotension. Neurology 51:1768-9

42. Mokri B, Aksamit AJ, Atkinson JL (2004) Paradoxical postural headaches in cerebrospinal fluid leaks. Cephalalgia 24:883-7

43. Mokri B, Atkinson JL, Piepgras DG (2000) Absent headache despite CSF volume depletion (intracranial hypotension). Neurology 55:1722-4

44. Lagrand TJ, Beukers R (2015) Sagging brain causing postural loss of consciousness: a case of severe spontaneous intracranial hypotension. Pract Neurol 15:471-3

45. Pleasure SJ, Abosch A, Friedman J, Ko NU, Barbaro N, Dillon W, Fishman RA, Poncelet AN (1998) Spontaneous intracranial hypotension resulting in stupor caused by diencephalic compression. Neurology 50:1854-7

46. Schievink WI, Moser FG, Pikul BK (2007) Reversal of coma with an injection of glue. Lancet 369:1402

47. Schievink WI (2003) Misdiagnosis of spontaneous intracranial hypotension. Arch Neurol 60:1713-8

48. Zada G, Solomon TC, Giannotta SL (2007) A review of ocular manifestations in intracranial hypotension. Neurosurg Focus 23:E8

49. Cheshire WJ, Wharen RJ (2009) Trigeminal neuralgia in a patient with spontaneous intracranial hypotension. Headache 49:770-3

50. Pakiam AS, Lee C, Lang AE (1999) Intracranial hypotension with parkinsonism, ataxia, and bulbar weakness. Arch Neurol 56:869-72

51. Russo A, Tessitore A, Cirillo M, Giordano A, De Micco R, Bussone G, Tedeschi $\mathrm{G}$ (2011) A transient third cranial nerve palsy as presenting sign of spontaneous intracranial hypotension. J Headache Pain 12:493-6

52. Hong M, Shah GV, Adams KM, Turner RS, Foster NL (2002) Spontaneous intracranial hypotension causing reversible frontotemporal dementia. Neurology 58:1285-7

53. Wicklund MR, Mokri B, Drubach DA, Boeve BF, Parisi JE, Josephs KA (2011) Frontotemporal brain sagging syndrome: an SIH-like presentation mimicking FTD. Neurology 76:1377-82

54. Griauzde J, Gemmete JJ, Chaudhary N, Wilson TJ, Pandey AS (2014) Largevolume blood patch to multiple sites in the epidural space through a single-catheter access site for treatment of spontaneous intracranial hypotension. AJNR Am J Neuroradiol 35:1841-6

55. Beck CE, Rizk NW, Kiger LT, Spencer D, Hill L, Adler JR (1998) Intracranial hypotension presenting with severe encephalopathy. Case report. J Neurosurg 89:470-3

56. Peng PW (2004) Intracranial hypotension with severe neurological symptoms resolved by epidural blood patch. Can J Neurol Sci 31:569-71 
57. Tian W, Zhang J, Chen J, Liu Y, Chen X, Wang N (2016) A quantitative study of intracranial hypotensive syndrome by magnetic resonance. Clin Neurol Neurosurg 141:71-76

58. Schievink WI, Maya MM, Louy C, Moser FG, Tourje J (2008) Diagnostic criteria for spontaneous spinal CSF leaks and intracranial hypotension. AJNR Am J Neuroradiol 29:853-6

59. Tyagi A (2016) Management of spontaneous intracranial hypotension. Pract Neurol 16:87-8

60. (2013) The International Classification of Headache Disorders, 3rd edition (beta version). Cephalalgia 33:629-808.

61. (2004) The International Classification of Headache Disorders: 2nd edition. Cephalalgia. 24 Suppl 1:9-160.

62. Mea E, Chiapparini L, Savoiardo M, Franzini A, Grimaldi D, Bussone G, Leone M (2009) Application of IHS criteria to headache attributed to spontaneous intracranial hypotension in a large population. Cephalalgia 29:418-22

63. Can OS, Yilmaz AA, Gurcan E, Alkis N, Uysalel A (2008) Is post partum headache after epidural anaesthesia always innocent? Eur J Anaesthesiol 25: 697-700

64. Schievink WI, Maya MM, Moser FM (2004) Treatment of spontaneous intracranial hypotension with percutaneous placement of a fibrin sealant. Report of four cases. J Neurosurg 100:1098-100

65. Rozen T, Swidan S, Hamel R, Saper J (2008) Trendelenburg position: a tool to screen for the presence of a low CSF pressure syndrome in daily headache patients. Headache 48:1366-71

66. Rabin BM, Roychowdhury S, Meyer JR, Cohen BA, LaPat KD, Russell EJ (1998) Spontaneous intracranial hypotension: spinal MR findings. AJNR Am J Neuroradiol 19:1034-9

67. Dillon WP (2001) Spinal manifestations of intracranial hypotension. AJNR Am J Neuroradiol 22:1233-4

68. Luetmer PH, Schwartz KM, Eckel LJ, Hunt CH, Carter RE, Diehn FE (2012) When should I do dynamic CT myelography? predicting fast spinal CSF leaks in patients with spontaneous intracranial hypotension. AJNR Am J Neuroradiol 33:690-4

69. Akbar JJ, Luetmer PH, Schwartz KM, Hunt CH, Diehn FE, Eckel LJ (2012) The role of MR myelography with intrathecal gadolinium in localization of spinal CSF leaks in patients with spontaneous intracranial hypotension. AJNR Am J Neuroradiol 33:535-40

70. Albayram S, Kilic F, Ozer H, Baghaki S, Kocer N, Islak C (2008) Gadoliniumenhanced MR cisternography to evaluate dural leaks in intracranial hypotension syndrome. AJNR Am J Neuroradiol 29:116-21

71. Vanopdenbosch LJ, Dedeken P, Casselman JW, Vlaminck SA (2011) MRI with intrathecal gadolinium to detect a CSF leak: a prospective open-label cohort study. J Neurol Neurosurg Psychiatry 82:456-8

72. Albes G, Weng H, Horvath D, Musahl C, Bazner H, Henkes H (2012) Detection and treatment of spinal CSF leaks in idiopathic intracranial hypotension. Neuroradiology 54:1367-73

73. Moriyama E, Ogawa T, Nishida A, Ishikawa S, Beck H (2004) Quantitative analysis of radioisotope cisternography in the diagnosis of intracranial hypotension. J Neurosurg 101:421-6

74. Weber WE, Heidendal GA, de Krom MC (1991) Primary intracranial hypotension and abnormal radionuclide cisternography. Report of a case and review of the literature. Clin Neurol Neurosurg 93:55-60

75. DRIPPS RD, VANDAM LD (1954) Long-term follow-up of patients who received 10,098 spinal anesthetics: failure to discover major neurological sequelae. J Am Med Assoc 156:1486-91

76. Bezov D, Ashina S, Lipton R (2010) Post-dural puncture headache: part II prevention, management, and prognosis. Headache: The Journal of Head and Face Pain 50:1482-1498

77. Sudlow C, Warlow C (2002) Epidural blood patching for preventing and treating post-dural puncture headache. Cochrane Database Syst Rev CD001791.

78. Kuczkowski KM (2007) The management of accidental dural puncture in pregnant women: what does an obstetrician need to know? Arch Gynecol Obstet 275:125-31

79. Dillon WP, Fishman RA (1998) Some lessons learned about the diagnosis and treatment of spontaneous intracranial hypotension. AJNR Am J Neuroradiol 19:1001-2

80. Couch JR (2008) Spontaneous intracranial hypotension: the syndrome and its complications. Curr Treat Options Neurol 10:3-11

81. Sencakova D, Mokri B, McClelland RL (2001) The efficacy of epidural blood patch in spontaneous CSF leaks. Neurology 57:1921-3
82. Berroir S, Loisel B, Ducros A, Boukobza M, Tzourio C, Valade D, Bousser MG (2004) Early epidural blood patch in spontaneous intracranial hypotension. Neurology 63:1950-1

83. van Kooten F, Oedit R, Bakker SL, Dippel DW (2008) Epidural blood patch in post dural puncture headache: a randomised, observer-blind, controlled clinical trial. J Neurol Neurosurg Psychiatry 79:553-8

84. Bart AJ, Wheeler AS (1978) Comparison of epidural saline placement and epidural blood placement in the treatment of post-lumbar-puncture headache. Anesthesiology 48:221-3

85. Zuspan FP (1960) Treatment of postpartum postspinal headache. Obstet Gynecol 16:21-6

86. Madsen SA, Fomsgaard JS, Jensen R (2011) Epidural blood patch for refractory low CSF pressure headache: a pilot study. J Headache Pain 12: 453-7

87. Leibold RA, Yealy DM, Coppola M, Cantees KK (1993) Post-dural-puncture headache: characteristics, management, and prevention. Ann Emerg Med 22:1863-70

88. JB G (1960) Treatment of post spinal headache. Anesthesiology. 565-566.

89. Ghavanini AA, Scott CA, Chan DK, Tang-Wai DF (2013) Management of patients with spontaneous intracranial hypotension causing altered level of consciousness: report of two cases and review of literature. Cephalalgia 33: 43-51

90. Stephen CD, Rojas R, Lioutas VA, Papavassiliou E, Simon DK (2016) Complicated spontaneous intracranial hypotension treated with intrathecal saline infusion. Pract Neurol 16:146-9

91. Geurts JW, Haanschoten MC, van Wijk RM, Kraak H, Besse TC (1990) Postdural puncture headache in young patients. A comparative study between the use of $0.52 \mathrm{~mm}$ (25-gauge) and $0.33 \mathrm{~mm}$ (29-gauge) spinal needles. Acta Anaesthesiol Scand 34:350-3

92. Sandesc D, Lupei MI, Sirbu C, Plavat C, Bedreag O, Vernic C (2005) Conventional treatment or epidural blood patch for the treatment of different etiologies of post dural puncture headache. Acta Anaesthesiol Belg 56:265-9

93. Vakharia SB, Thomas PS, Rosenbaum AE, Wasenko JJ, Fellows DG (1997) Magnetic resonance imaging of cerebrospinal fluid leak and tamponade effect of blood patch in postdural puncture headache. Anesth Analg 84: 585-90

94. Frank RL (2008) Lumbar puncture and post-dural puncture headaches: implications for the emergency physician. J Emerg Med 35:149-57

95. Cook MA, Watkins-Pitchford JM (1990) Epidural blood patch: a rapid coagulation response. Anesth Analg 70:567-8

96. Turnbull DK, Shepherd DB (2003) Post-dural puncture headache: pathogenesis, prevention and treatment. Br J Anaesth 91:718-29

97. Barrios-Alarcon J, Aldrete JA, Paragas-Tapia D (1989) Relief of post-lumbar puncture headache with epidural dextran 40: a preliminary report. Reg Anesth 14:78-80

98. Szeinfeld M, Ihmeidan IH, Moser MM, Machado R, Klose KJ, Serafini AN (1986) Epidural blood patch: evaluation of the volume and spread of blood injected into the epidural space. Anesthesiology 64:820-2

99. Watanabe K, Hashizume K, Kawaguchi M, Fujiwara A, Sasaoka N, Furuya H (2011) Fluoroscopically guided epidural blood patch with subsequent spinal $\mathrm{CT}$ scans in the treatment of spontaneous cerebrospinal fluid hypovolemia. J Neurosurg 114:1731-5

100. Hayek SM, Fattouh M, Dews T, Kapural L, Malak O, Mekhail N (2003) Successful treatment of spontaneous cerebrospinal fluid leak headache with fluoroscopically guided epidural blood patch: a report of four cases. Pain Med 4:373-8

101. Kranz PG, Gray L, Taylor JN (2011) CT-guided epidural blood patching of directly observed or potential leak sites for the targeted treatment of spontaneous intracranial hypotension. AJNR Am J Neuroradiol 32:832-8

102. Patel MR, Caruso PA, Yousuf N, Rachlin J (2000) CT-guided percutaneous fibrin glue therapy of cerebrospinal fluid leaks in the spine after surgery. AJR Am J Roentgenol 175:443-6

103. DiGiovanni AJ, Dunbar BS (1970) Epidural injections of autologous blood for postlumbar-puncture headache. Anesth Analg 49:268-71

104. Abouleish E, Vega S, Blendinger I, Tio TO (1975) Long-term follow-up of epidural blood patch. Anesth Analg 54:459-63

105. Brownridge $P$ (1983) The management of headache following accidental dural puncture in obstetric patients. Anaesth Intensive Care 11:4-15

106. Crawford JS (1980) Experiences with epidural blood patch. Anaesthesia 35: $513-5$ 
107. Crawford JS (1981) Headache after lumbar puncture. Lancet 2:418

108. Ohtonari T, Ota S, Nishihara N, Ota T, Tanaka Y, Sekihara Y, Tanaka A (2012) A novel technique of multiple-site epidural blood patch administration for the treatment of cerebrospinal fluid hypovolemia. J Neurosurg 116:1049-53

109. Canas N, Medeiros E, Fonseca AT, Palma-Mira F (2004) CSF volume loss in spontaneous intracranial hypotension. Neurology 63:186-7

110. Vercauteren MP, Hoffmann VH, Mertens E, Sermeus L, Adriaensen HA (1999) Seven-year review of requests for epidural blood patches for headache after dural puncture: referral patterns and the effectiveness of blood patches. Eur J Anaesthesiol 16:298-303

111. Mokri B (2002) Intracranial hypertension after treatment of spontaneous cerebrospinal fluid leaks. Mayo Clin Proc 77:1241-6

112. Kantor D, Silberstein SD (2005) Cervical epidural blood patch for low CSF pressure headaches. Neurology 65:1138

113. Diaz JH (2002) Permanent paraparesis and cauda equina syndrome after epidural blood patch for postdural puncture headache. Anesthesiology 96:1515-7

114. Kawamata T, Omote K, Matsumoto M, Toriyabe M, Ito T, Namiki A (2003) Pneumocephalus following an epidural blood patch. Acta Anaesthesiol Scand 47:907-9

115. Perez M, Olmos M, Garrido FJ (1993) Facial nerve paralysis after epidural blood patch. Reg Anesth 18:196-8

116. Lavi R, Yarnitsky D, Rowe JM, Weissman A, Segal D, Avivi I (2006) Standard vs atraumatic Whitacre needle for diagnostic lumbar puncture: a randomized trial. Neurology 67:1492-4

117. Strupp M, Schueler O, Straube A, Von Stuckrad-Barre S, Brandt T (2001) "Atraumatic" Sprotte needle reduces the incidence of post-lumbar puncture headaches. Neurology 57:2310-2

118. Armon C, Evans RW (2005) Addendum to assessment: prevention of postlumbar puncture headaches: report of the therapeutics and technology assessment subcommittee of the american academy of neurology. Neurology 65:510-2

119. Holst D, Mollmann M, Ebel C, Hausman R, Wendt M (1998) In vitro investigation of cerebrospinal fluid leakage after dural puncture with various spinal needles. Anesth Analg 87:1331-5

120. Thomas SR, Jamieson DR, Muir KW (2000) Randomised controlled trial of atraumatic versus standard needles for diagnostic lumbar puncture. BMJ 321:986-90

121. Luostarinen L, Heinonen T, Luostarinen M, Salmivaara A (2005) Diagnostic lumbar puncture. Comparative study between 22-gauge pencil point and sharp bevel needle. J Headache Pain 6:400-4

122. Flaatten H, Raeder J (1985) Spinal anaesthesia for outpatient surgery. Anaesthesia 40:1108-11

123. Flaatten H, Rodt S, Rosland J, Vamnes J (1987) Postoperative headache in young patients after spinal anaesthesia. Anaesthesia 42:202-5

124. Tourtellotte WW, Henderson WG, Tucker RP, Gilland O, Walker JE, Kokman E (1972) A randomized, double-blind clinical trial comparing the 22 versus 26 gauge needle in the production of the post-lumbar puncture syndrome in normal individuals. Headache 12:73-8

125. Richman JM, Joe EM, Cohen SR, Rowlingson AJ, Michaels RK, Jeffries MA Wu CL (2006) Bevel direction and postdural puncture headache: a metaanalysis. Neurologist 12:224-8

126. Corbey MP, Bach AB, Lech K, Frorup AM (1997) Grading of severity of postdural puncture headache after 27-gauge Quincke and Whitacre needles. Acta Anaesthesiol Scand 41:779-84

127. Reina MA, de Leon-Casasola OA, Lopez A, De Andres J, Martin S, Mora M (2000) An in vitro study of dural lesions produced by 25-gauge Quincke and Whitacre needles evaluated by scanning electron microscopy. Reg Anesth Pain Med 25:393-402

128. Kuntz KM, Kokmen E, Stevens JC, Miller P, Offord KP, Ho MM (1992) Postlumbar puncture headaches: experience in 501 consecutive procedures. Neurology 42:1884-7

129. Jarvis AP, Greenawalt JW, Fagraeus $L$ (1986) Intravenous caffeine for postdural puncture headache. Anesth Analg 65:316-7

130. Yucel A, Ozyalcin S, Talu GK, Yucel EC, Erdine S (1999) Intravenous administration of caffeine sodium benzoate for postdural puncture headache. Reg Anesth Pain Med 24:51-4

131. Bussone G, Tullo V, D'Onofrio F, Petretta V, Curone M, Frediani F, Tonini C, Omboni S (2007) Frovatriptan for the prevention of postdural puncture headache. Cephalalgia 27:809-13

132. MacArthur C, Lewis M, Knox EG (1993) Accidental dural puncture in obstetric patients and long term symptoms. BMJ 306:883-5

\section{Submit your manuscript to a SpringerOpen ${ }^{\circ}$ journal and benefit from:}

- Convenient online submission

- Rigorous peer review

Immediate publication on acceptance

- Open access: articles freely available online

- High visibility within the field

- Retaining the copyright to your article

Submit your next manuscript at $\gg$ springeropen.com 